\title{
AZITHROMYCIN VERSUS CEFTRIAXONE- WHICH IS BETTER IN UNCOMPLICATED TYPHOID FEVER? A CLINICAL TRIAL IN A TERTIARY CARE HOSPITAL
}

\author{
Vishwanath Machakanur' ${ }^{1}$, Rohit $S^{2}$
}

${ }^{1}$ Assistant Professor, Department of Paediatrics, KAHER's Jawaharlal Nehru Medical College, Belagavi, Karnataka, India.

2Postgraduate Student, Department of Paediatrics, KAHER's Jawaharlal Nehru Medical College, Belagavi, Karnataka, India.

ABSTRACT
BACKGROUND
Enteric fever has been very a common and many times a fatal infective disease found in developing countries and has been known
to have increasing resistance to novel drugs. So, there is an urgent need for a simple, therapeutic, cost-effective medicine to treat
typhoid fever \& to prevent further drug resistance.

\section{METHODS}

It is a non-randomized, case-control study done in Paediatrics department of Dr. Prabhakar Kore Hospital \& Research centre of KAHER (KLE Academy of Higher Education and Research), attached to J N Medical College, Belagavi, over a period of 18 months from June 2017 to December 2018. The study included 200 children (2-17 years of age) with positive Widal result, uncomplicatedenteric fever; in this cohort, 100 children were treated using (oral, low dose, for short duration of 6 days) Azithromycin and remaining 100 children were treated with (intravenous, 7 days) Ceftriaxone. Each child was assessed clinically every day, \& study results were captured as clinical and microbiological cure or failure, at the end of either drug regimens. This descriptive data was statistically analysed in SPSS-20.0 software. The p-value of $<0.05$ was taken as significant statistically.

\section{RESULTS}

Periods required by children for responding to drug therapy and to became afebrile i.e., defervescence were significantly ( $p=0.000$ ) less with Azithromycin receiving group than ceftriaxone receiving group. 95\% of children who received azithromycin showed defervescence by $5^{\text {th }}$ day of regimen but, only $29 \%$ of children receiving ceftriaxone attained defervescence by $5^{\text {th }}$ day of regimen. There was no microbiological clearance at $10^{\text {th }}$ day in only one case of ceftriaxone trial-group. Significantly $(p=0.027)$ there was early clinical cure in azithromycin trial group as compared to ceftriaxone trial group. The microbiological cure was not comparable in either groups $(\mathrm{p}=0.135)$.

\section{CONCLUSION}

At the end we come to the conclusion that oral Azithromycin $(10 \mathrm{mg} / \mathrm{kg} /$ day, once a day for 6 days) is more efficacious in uncomplicated-typhoid fever management as compared to intravenous ceftriaxone $(100 \mathrm{mg} / \mathrm{kg} /$ day in 2 divided doses for 7 days) in children and adolescents of 2 to 17 years age group.

HOW TO CITE THIS ARTICLE: Machakanur V, Rohit S. Azithromycin versus ceftriaxone- which is better in uncomplicated typhoid fever? a clinical trial in a tertiary care hospital. J. Evolution Med. Dent. Sci. 2019;8(17):1394-1398, D0I: $10.14260 /$ jemds/2019/310

\section{BACKGROUND}

Enteric fever caused by Salmonella typhi and paratyphi has been a very common and often fatal disease in children of developing countries. There is an incidence of 500 cases/lakh population $(0.5 \%)$ and a high mortality rate. ${ }^{1,2}$ As per the World Health Organization at least 12.5 million cases of typhoid are diagnosed worldwide annually.3,4

For many decades, chloramphenicol has been drug of choice for enteric fever. ${ }^{5}$ But it is also found that many resistant strains have been emerging recently. Thus, there is need for any other treatment options. ${ }^{6}$

Fluoroquinolone resistant strains of Salmonella typhi have been isolated \& documented. Ceftriaxone (A $3^{\text {rd }}$

'Financial or Other Competing Interest': None.

Submission 22-03-2019, Peer Review 20-04-2019,

Acceptance 23-04-2019, Published 29-04-2019.

Corresponding Author:

Dr. Vishwanath Machakanur,

Chandra-Kamala, H. No. 39A,

P\&T Colony, $2^{\text {nd }}$ Stage,

Hanuman Nagar,

Belgaum-590019,

Karnataka, India

E-mail:vlmjnmc@gmail.com

DOI: $10.14260 / \mathrm{jemds} / 2019 / 310$ generation cephalosporin) is highly effective in enteric fever; but every time it is supposed to be administered parenterally; hence, considered as lesser ideal treatment option in enteric fever.

Many studies have shown that the azithromycin concentration in neutrophils are more than 100-fold the serum level. It is also recently found that azithromycin given once daily appears to be helpful in treatment of typhoidfever. ${ }^{7}$ If these results are confirmed, in developing countries where in resources are limited, oral azithromycin could be a convenient alternative drug for the treatment of typhoid fever.

Therefore, we hereby provide a simple study for a clinically effective drug in treatment of typhoid fever (Uncomplicated): comparing oral Azithromycin with intravenous Ceftriaxone.

\section{METHODS}

A sum of 200 Widal positive uncomplicated typhoid fever children were considered for this study in age group of 2-17 years who were admitted in the paediatric department of Dr Prabhakar Kore Hospital \& Research of KAHER, attached to J. N. Medical College, Belagavi, over a period of 18 months June 2017 to December 2018. 
All these were enrolled in the study with their parents' consent. Each child was enrolled in separate proformas including the demographic data, chief complaints, associated symptoms, WIDAL test titres, and temperature recordings. This cohort was divided into 2 equal groups: Azithromycin receiving group (Receiving $10 \mathrm{mg} / \mathrm{kg} /$ day, orally, once day for 6 days) and Ceftriaxone receiving group $100 \mathrm{mg} / \mathrm{kg} /$ day, intravenous, in 2 DD for 7 days) as a basic treating drug for typhoid. Investigations done were: complete blood count, blood-culture (On day 1 and day 10 to correlate the treatment outcomes- clinically and microbiologically) using the standardised culture-method (XLD-agar).

Each patient was examined clinically, evaluated and proforma was updated and some data was captured (Appetite, headache, temperature (Axillary), abdominal-pain, constipation/diarrhoea, hepatomegaly, and splenomegaly). Adverse reactions of Azithromycin and Ceftriaxone were searched for and if present, the drug was replaced by a safer alternative \& subsequently the patient was excluded from this study. Patients were receiving in-patient care for entire treatment period and the study result was captured as clinical and microbiological cure and failure respectively. This data was analysed as Contingency co-efficient or Chi-square test, Independent samples ' $\mathrm{t}$ ' test using the SPSS-20.0 software. $<0.05$ p-value was considered statistically significant.

\section{RESULTS}

Total 200 patients in male: female ratio of $1.2: 1$ with positive WIDAL were enrolled in the study at admission to hospital. The mean age of subjects of azithromycin receiving group was 7.3 years \& that for ceftriaxone receiving group was 8.6 years. The male: female ratio was 1.02:1 in azithromycin receiving group \& 1.1:1 in ceftriaxone receiving group.

\section{Symptoms and Signs}

There was no significant difference between the two drug receiving children with respect to demographic data \& pretreatment laboratory results. Fever was the chief complaint in all these cases (With a mean duration of 9.36 days in azithromycin receiving group; 10.5 days in ceftriaxone receiving group).

\section{Laboratory Parameters Comparison}

The mean haemoglobin in Azithromycin trial group was 12.2 $\mathrm{gm} / \mathrm{dL}$ and for ceftriaxone trial group was $11.16 \mathrm{gm} / \mathrm{dL}$. The mean total leucocyte count was $6,134 / \mathrm{cu} \mathrm{mm}$ in Azithromycin trial group whereas in ceftriaxone trial group it was $5,609 / \mathrm{cu} \mathrm{mm}$. the mean platelet count was $2.16 \mathrm{lakh} / \mathrm{cu}$ $\mathrm{mm}$ in azithromycin trial group as compared to $3.8 \mathrm{lakh} / \mathrm{cu}$ $\mathrm{mm}$ in ceftriaxone receiving group. The Leucopenia (WBCs $<4000 / \mathrm{cu} \mathrm{mm}$ ) was documented in only $28 \%$ of Azithromycin receiving group and $22.2 \%$ of ceftriaxone receiving group.

\section{Daily Monitoring \& Evaluation Comparison (Table 1)}

Number of days taken to become afebrile i.e., defervescence was significantly less with azithromycin receiving group as compared with Ceftriaxone receiving group, also it was statistically significant $(\mathrm{p}=0.000)$.

The mean defervescence time was 2.72 days in azithromycin receiving group and 5.52 days in ceftriaxone receiving group. On $5^{\text {th }}$ day of hospitalization, patients receiving azithromycin showed 95\% defervescence whereas patients receiving ceftriaxone had defervescence only in $29 \%$ cases-

- One of the presenting symptoms was diarrhoea which responded well in azithromycin treatment group (100\% by $3^{\text {rd }}$ day) better than ceftriaxone treatment group ( $92 \%$ by $3^{\text {rd }}$ day) ( $\mathrm{p}=0.002$ ).

- Anorexia which was one of the symptoms was relieved by $3^{\text {rd }}$ day in $96 \%$ of cases treated using azithromycin but only $56 \%$ of cases treated using ceftriaxone; it was statistically significant $(\mathrm{p}=0.001)$.

- $\quad$ Coated-tongue was a common sign found in typhoid, was cleared early with azithromycin treatment as compared to ceftriaxone treatment but was not found to be statistically significant $(\mathrm{p}=0.2)$.

- There were no adverse reactions observed in both the study groups.

- The patient compliance to take azithromycin was better as compared to intravenous ceftriaxone

\section{Blood-Culture Comparison}

- The blood culture yield was $12 \%$ in this study.

- Five out of $100(5 \%)$ azithromycin received patients and seven out of $100(7 \%)$ ceftriaxone received patients had positive blood culture of salmonella organisms. This blood culture was done on $1^{\text {st }}$ day of admission before antibiotic usage.

- $\quad$ Two cultures (2\%) of ceftriaxone receiving patients did isolate salmonella organisms even on $10^{\text {th }}$ day of treatment.

- All culture sensitivities were sensitive to ceftriaxone, azithromycin \&ciprofloxacin

- 1 culture organism had resistance to cotrimoxazole, two were resistant to ampicillin\& three were resistant to chloramphenicol.

\section{Comparative Outcome of The Study: (Table 2)}

- It was observed that there was early clinical cure in cases treated with azithromycin than those with ceftriaxone, also was significant statistically ( $\mathrm{p}=0.027)$.(Fig 1)

- $\quad$ The bacterial clearance in blood culture on $10^{\text {th }}$ day was defined as microbiological cure, was not much differing in both study groups $(\mathrm{p}=0.131)$. 


\begin{tabular}{|c|c|c|c|c|c|c|c|c|}
\hline \multirow[b]{3}{*}{ Clinical Features } & \multicolumn{8}{|c|}{ Resolution of Symptoms and Signs } \\
\hline & \multicolumn{2}{|c|}{ Day 1 N (\%) } & \multicolumn{2}{|c|}{ Day 3 N (\%) } & \multicolumn{2}{|c|}{ Day 5 N (\%) } & \multicolumn{2}{|c|}{ Day 7 N (\%) } \\
\hline & 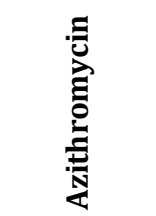 & 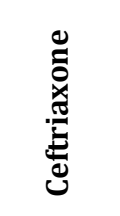 & 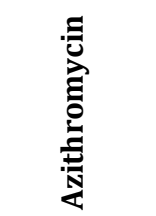 & 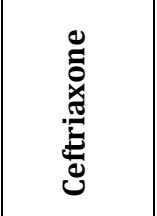 & 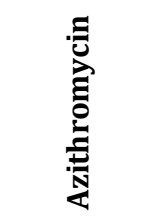 & 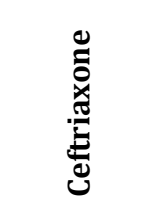 & 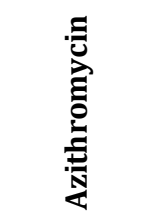 & 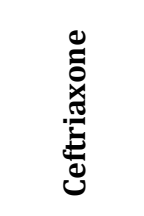 \\
\hline Fever & $0(0)$ & $0(0)$ & $96(96)$ & $2(4)$ & $95(95)$ & $29(29)$ & $49(98)$ & $46(92)$ \\
\hline Abdominal pain & $60(60)$ & $74(74)$ & $100(100)$ & $82(82)$ & $100(100)$ & $100(100)$ & $100(100)$ & $100(100)$ \\
\hline Constipation & $100(100)$ & $45(90)$ & $100(100)$ & $98(98)$ & $100(100)$ & $100(100)$ & $100(100)$ & $100(100)$ \\
\hline Diarrhoea & $78(78)$ & $42(84)$ & $100(100)$ & $90(90)$ & $100(100)$ & $100(100)$ & $100(100)$ & $100(100)$ \\
\hline Melena & $100(100)$ & $49(98)$ & $100(100)$ & $100(100)$ & $100(100)$ & $100(100)$ & $100(100)$ & $100(100)$ \\
\hline Anorexia & $68(68)$ & $32(64)$ & $96(96)$ & $76(76)$ & $96(96)$ & $90(90)$ & $100(100)$ & $98(98)$ \\
\hline Coated tongue & $44(44)$ & $42(42)$ & $88(88)$ & $50(50)$ & $98(98)$ & $88(88)$ & $100(100)$ & $98(98)$ \\
\hline Abdominal tenderness & $100(100)$ & $86(86)$ & $100(100)$ & $90(90)$ & $100(100)$ & $100(100)$ & $100(100)$ & $100(100)$ \\
\hline Hepatomegaly & $54(54)$ & $57(57)$ & $82(82)$ & $54(54)$ & $98(98)$ & $84(84)$ & $100(100)$ & $94(94)$ \\
\hline Splenomegaly & $28(28)$ & $48(48)$ & $70(70)$ & $48(48)$ & $98(98)$ & $80(80)$ & $100(100)$ & $98(98)$ \\
\hline
\end{tabular}

Table 1. Comparison of Symptoms and Signs Between Azithromycin and Ceftriaxone Receiving Groups

\begin{tabular}{|c|c|}
\hline Drug Susceptible & Percentage \\
\hline Amoxycillin & 100 \\
\hline Cefixime & 100 \\
\hline Ceftriaxone & 100 \\
\hline Azithromycin & 90 \\
\hline Chloramphenicol & 60 \\
\hline Cotrimoxazole & 16 \\
\hline Ampicillin & 50 \\
\hline Ciprofloxacin & 78 \\
\hline Ofloxacin & 85 \\
\hline Table 2. In Vitro Susceptibility/Blood Culture Sensitivity of Salmonella Isolates from Culture Positive Subjects \\
\hline
\end{tabular}

\begin{tabular}{|c|c|c|c|}
\hline Cure & Azithromycin Trial Group & Ceftriaxone Trial Group & p-Value \\
\hline Clinical cure & $98(98 \%)$ & $86(86 \%)$ & 0 \\
\hline Clinical failure & $2(2 \%)$ & $14(14 \%)$ & 0.027 \\
\hline \multicolumn{4}{|c|}{ Table 3. Clinical Outcome Comparison } \\
\hline
\end{tabular}

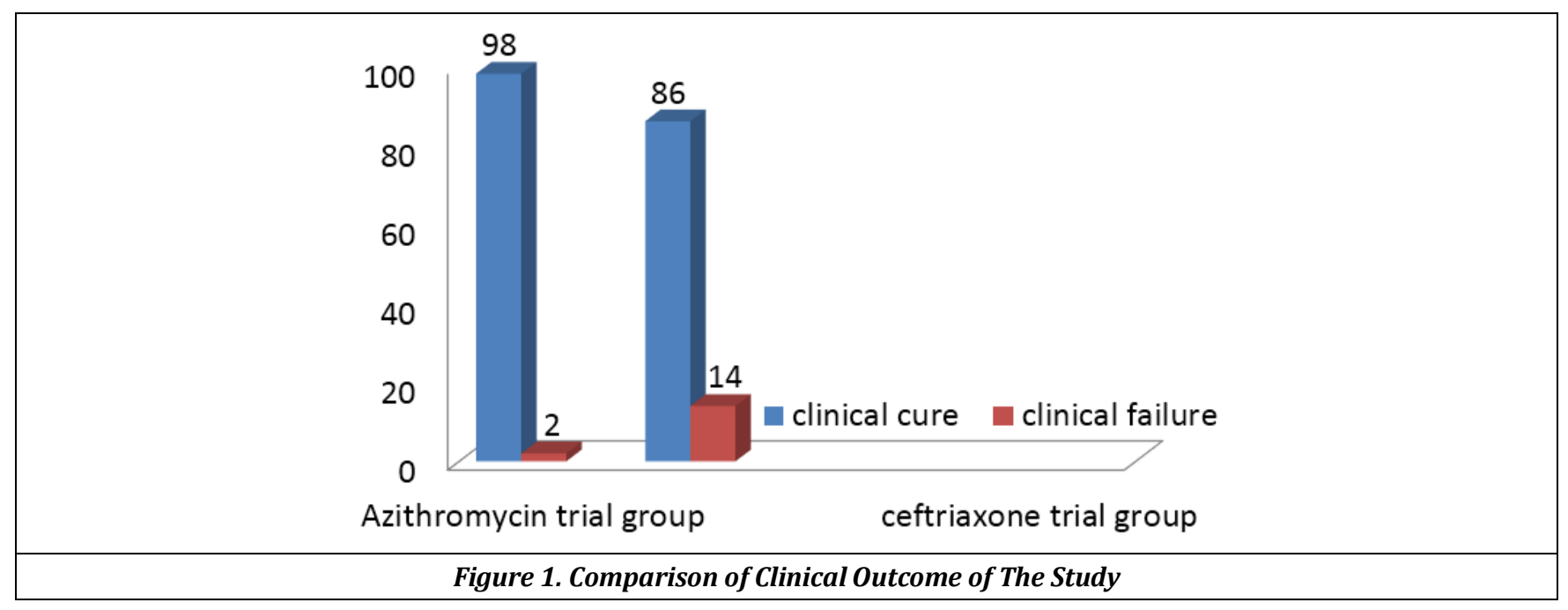

\section{DISCUSSION}

This study compares the clinical \& microbiological efficacy of oral Azithromycin with Intravenous ceftriaxone in treating children who had uncomplicated typhoid fever in age group of 2 to 17 years, admitted Paediatric department of Dr. Prabhakar Kore Hospital \& Research Unit of KAHER, attached to J N Medical College, Belagavi. 
The two study groups were not differing in demographic data and chief complaints; were comparable. There was even distribution of severity of symptom in both the study groups, as even observed in other similar studies.7,8,9

The 2 groups (Azithromycin and ceftriaxone receiving) were found comparable in all demographic data, presentation and were not significant statistically. Typhoid severity was equally distributed in both the groups. The complaint of fever in both treatment groups were in days (9-11 days) reported in prior published trials on the treatment of typhoid.7,8,9

In present study, blood culture was done before first antibiotic dose after hospitalisation and second on $10^{\text {th }}$ day of admission irrespective of the clinical outcome. Another similar study by Tribble D et. al., practiced blood culture sampling in between the study on $3^{\text {rd }}$ and $7_{\text {th }}$ day.

Our study has persistent bacteraemia (1 out of 5 culture positive) i.e., among ceftriaxone receiving patients 1 out of 5 cultures were still growing salmonella on $10^{\text {th }}$ day of treatment. This finding is not similar to the study of typhoid fever using chloramphenicol and ceftriaxone comparatively, where 3rd day blood cultures for chloramphenicol receiving patients were still positive and those of ceftriaxone receiving patients were cleared ( 0 out of 28 ). ${ }^{10}$

Another very interesting finding we had was there was no correlation between in vitro resistance and in vivo effectiveness against Enteric fever. The possible reason being serum drug levels determine sensitivity/ susceptibility tests, but the main drug action of azithromycin is intracellular bactericidal action. Sometimes intracellular azithromycin levels increase to 100 times than of serum levels, 11,12

Similar study result was explained by Robert W Frenc k Jr et al. in a study. 13

In our study we had documented a Relapse case who was treated with intravenous ceftriaxone. There were no relapses in azithromycin received group. The possible explanation for no relapses in azithromycin received patients is that, the azithromycin concentration being high intracellularly, its secretion in biliary tree and a relatively longer half-life.8,14,15

Another similar trial conducted by Tribble D et.al., concluded that the high dose azithromycin for a short duration $(20 \mathrm{mg} / \mathrm{kg} /$ day, maximum $1000 \mathrm{mg} /$ day, for 5 days $)$ is effective in treating enteric fever of uncomplicated type in children.13,15 A trial by Agarwal A et.al., in 2000 documented safe and effective therapeutic role of azithromycin (6days short course) in typhoid fever. ${ }^{16}$

In the current study a low dose Azithromycin is used for a short duration $(10 \mathrm{mg} / \mathrm{kg} /$ day, OD, for 6 days) the reason being the possible adverse effects of high dose azithromycin. A study done by Saha S K et.al., used low dose azithromycin with no comparison with any other drugs; found to be effective in treating enteric fever in children. ${ }^{17}$

Based on parents' opinion, frequent need of intravascular access was a reason for non-compliance and oral once a day Azithromycin increased the compliance. Similar observations were quoted in studies of Robert W Frenck Jr et.al.13,12,17

A much recent study from Vietnam reported that the decreased duration of azithromycin therapy can be equally effective in treating adult typhoid fever. ${ }^{17}$ This result encouraged us to use low dose, short duration Azithromycin in childhood enteric fevers.

Thus, our study clearly shows that the clinical cure is better in low dose, short duration oral Azithromycin regimen than conventional intravenous ceftriaxone regimen; this observation was significant statistically $(p=0.026)$. But the microbiological-cure was still comparable between two groups $(p=0.132)$. Five more studies showed similarity in clinical and microbiological cures using oral Azithromycin and even there were microbiological-cure rates exceeding $90 \%$ without any significant adverse drug reactions or relapses in typhoid fever.7,15,16

\section{CONCLUSIONS}

A short course of oral Azithromycin $(10 \mathrm{mg} / \mathrm{kg} /$ day once a day for 6 days) is more efficacious in treating uncomplicated typhoid fever as compared to intravenous ceftriaxone $(100$ $\mathrm{mg} / \mathrm{kg} /$ day in 2 DD for 7 days) in children and adolescents.

\section{Study Limitations}

1. In this study, we could not effectively describe the microbiological outcome, because blood culture yield was poor (only 12\%), it is very much less than that described in the text books. Prior administration of antibiotics before admission to the study hospital was not addressed, which might have affected the culture results in the study.

2. Further multicentric trials with larger sample-size is recommended.

\section{Acknowledgement}

We are thankful to the staff, postgraduates and ethical committee of the department of paediatrics, Dr. Prabhakar Kore Hospital \& Research Unit, attached to KAHER's J N Medical College, Belagavi, for making this research work a success. We are very thankful to the hospital laboratory. We are grateful to all the children \& their parents who participated in the study. This study was funded by the authors.

\section{REFERENCES}

[1] Byrne JP. Encyclopedia of pestilence, pandemics and plagues. Westport, Connecticut: Greenwood Press 2008;1(A-M):190.

[2] USAMRMC: 50 years of dedication to the warfighter: 1958-2008. U.S. Army Medical Research and Material Command Headquarters, Government Publication 2008: p. 5.

[3] Choo KE, Davies TME, Ismail A, et al. Rapid and reliable serological diagnosis of enteric fever: comparative sensitivity and specificity of Typhidot and Typhidot-M tests in febrile Malaysian children. Acta Tropica 1999;72(2):175-83.

[4] Fuller GW. Description of the process and plant of the Jersey City water supply company for the sterilization of the water of the Boonton reservoir. Proceedings American Water Works Association 1909: p. 110-34.

[5] Bhutta ZA. Salmonella. In: Behrman, Kliegman, Jenson, et al. eds. Nelson Text Book of Pediatrics. 18 ${ }^{\text {th }}$ edn. Philadelphia, PA: Elsevier/Saunders 2011: p. 1186-90.

[6] Bhutta ZA, Mansurali N. Rapid serologic diagnosis of pediatric typhoid fever in an endemic area: a prospective comparative evaluation of two dotenzyme immunoassays and the Widal test. The 
American Journal of Tropical Medicine and Hygiene 1999;61(4):654-7.

[7] Frenck RW Jr, Nakhla I, Sultan Y, et al. Azithromycin versus ceftriaxone for the treatment of uncomplicated typhoid fever in children. Clin Infect Dis 2000;31(5):1134-8.

[8] Chinh NT, Parry CM, Ly NT, et al. A randomized controlled comparison of azithromycin and ofloxacin for treatment of multidrug-resistant or nalidixic acidresistant enteric fever. Antimicrob Agents Chemother 2000;44(7):1855-9.

[9] Islam A, Butler T, Kabir I, et al. Treatment of typhoid fever with ceftriaxone for 5 days or chloramphenicol for 14 days: a randomized clinical trial. Antimicrob Agents Chemother 1993;37(8):1572-5.

[10] Girgis NI, Butler T, Frenck RW, et al. Azithromycin versus ciprofloxacin for treatment of uncomplicated typhoid fever in a randomized trial in Egypt that included patients with multidrug resistance. Antimicrob Agents Chemother 1999;43(6):1441-4.

[11] Butler T, Sridhar CB, Daga MK. Treatment of typhoid fever with azithromycin versus chloramphenicol in a randomized multicentre trial in India. J Antimicrob Chemother 1999;44(2):243-50.
[12] Rahman M. Treatment of enteric fever. The ORION Med J 2009;32(3):674.

[13] Tribble D, Girgis N, Habib N, et al. Efficacy of azithromycin for typhoid fever. Clin Infect Dis 1995;21(4):1045-6.

[14] Wildfeuer A, Laufen H, Zimmermann T. Distribution of orally administered azithromycin in various blood compartments. Int $\mathrm{J}$ Clin Pharmacol Ther 1994;32(7):356-60.

[15] Rakita RM, Jacques-Palaz K, Murray BE. Intracellular activity of azithromycin against bacterial enteric pathogens. Antimicrob Agents Chemotherapy 1994;38(9):1915-21.

[16] Aggarwal A, Ghosh A, Gomber S, et al. Efficacy and safety of azithromycin for uncomplicated typhoid fever: an open label non-comparative study. Indian Pediatrics 2011;48(7):553-6.

[17] Saha SK, Talukder SY, Islam M, et al. A highly ceftriaxone resistant Salmonella typhi in Bangladesh. Pediatric Infectious Disease Journal 1999;18(4):387. 